\title{
Intermunicipal risk management: Addressing territorial and local expectations
}

\author{
A.O. Tavares \\ Centre for Social Studies and Earth Sciences Department, University of Coimbra, Portugal \\ P.P. Santos \& J. Lopes \\ Centre for Social Studies, University of Coimbra, Portugal
}

J. Brito

Intermunicipal Community of the Coimbra Region, Portugal

\begin{abstract}
The Intermunicipal Community of the Coimbra Region is a public administrative entity that gathers 19 municipalities of Central Portugal. As part of its competences, the Community assumed the objective of complementing the current emergency planning instruments by strengthening the local and regional intervention in the areas of prevention, contingency and recovery, a process that culminates in the elaboration of an Intermunicipal Risk Management Plan. Several phases were conducted as part of the knowledge building process, considering a risk management approach. Municipal and district emergency plans were analyzed, identifying intervention areas where both plans could be articulated. Relevant sectorial planning instruments (mobility, water, forest and urban planning, among others) were analyzed in order to propose procedures that can improve the contingency of strategic, vital and day-to-day activities. A workshop with local municipal risk practitioners was conducted, following a Q-Methodology approach, where constraints and strengths of current emergency planning were identified, and future expectations on the intermunicipal role in risk management were assembled. Existing and new susceptibility maps were produced for specific relevant risks (fog and ice cover, for example). Finally, territorial vulnerability was assessed through principal component analysis identifying vulnerability drivers to be addressed in risk reduction measures and long term policies. The definition of a strategy for the intermunicipal management of risks has been a fruitful challenge for managers, stakeholders and institutions that reflects a broader perspective in risk governance for the region.
\end{abstract}

\section{INTRODUCTION}

Risk management must respond to countless political, economic and social pressures, a process in which municipal authorities must choose among competing priorities and selectively allocate scarce resources to a limited set of problems (Henstra, 2010). As explained by Hassel (2012), risk management needs to be regarded and considered as a system, in order to increase the resilience of complex territories, focusing on the maintenance of multifunctionality and assuring the participation of the stakeholders and citizens (Pech et al., 2016).

The population growth, increasing exposure, nonplanned urbanization, along with the occurrence of disasters related to extreme events have led to an increase of impacts over the last decades (UNISDR, 2015), which underlined the risk-based approach, where risk pre-assessment, characterization, analysis, judgement and management, transversally, thinking and practicing multi-stakeholder involvement, are fundamental steps to disaster risk reduction (IRGC, 2005; Aven and Renn, 2010). Risk knowledge acquisition and integration in risk management are crucial to be applied in the risk governance-related decision making process (IRGC, 2005).

Communities are key participants, but often overlooked resources, in both proactive and reactive phases of emergency management (Murphy, 2007). At this local scale, municipalities are required to use analysis to develop long-term goals, strategies, priorities and plans for following up its work relating to societal safety and emergency preparedness (Flage \& Amundrud, 2015). The challenge to make plans more functional and relevant and ensure that their content is adequate for the task of predisposing resources during emergencies is a goal for risk managers (Alexander, 2005). The application of recognized standards to the emergency planning is a guarantee of the compatibility between plans and the different purposes or jurisdictions. 
Using a risk-based approach, the Intermunicipal Community (CIM) of the Coimbra Region, Portugal, understands long-term goals, strategies, priorities and plans for risk management as a central focus for competing priorities and selectively to allocate resources.

This intermunicipal public administrative entity, that gathers 19 municipalities of Central Portugal, a region characterized by diverse geographical and societal features, considered the design of a functional risk plan as a key to improve the societal safety and emergency preparedness.

As part of its competences, the CIM of the Coimbra region assumed the objective of complementing the current emergency planning instruments by strengthening the local and regional intervention in the areas of prevention, contingency and recovery (Fig. 1). This process will ultimately conduct to the elaboration of the Intermunicipal Risk Management Plan (IRMP), where the articulation of resources and efficiency in communication, at the intermunicipal and regional level, are key elements. The steps of knowledge production, supporting the elaboration of the IRMP, are focusing on the maintenance of multifunctionality, adding complementary competences to be articulated with the existing plans, which are materially focused mainly on emergency response (Figure 1).

As part of the assessment phase of the process, several tasks aiming at improving the knowledge about risk, the current risk management practices, as well as the future expectations in regard to intermunicipal risk management, were carried out. This included the analysis of current emergency plans and sectorial planning instruments (mobility, spatial planning, etc.) and their incompatibilities; the realization of a workshop with municipal disaster risk reduction managers and practitioners, evaluating the expectations about the IRMP; the inventory and analysis of current susceptibility maps and damage databases; and the assessment of territorial vulnerability at the local scale. Territorial vulnerability was assessed, identifying vulnerability drivers to be addressed by the risk management plan and forming the decision making process.

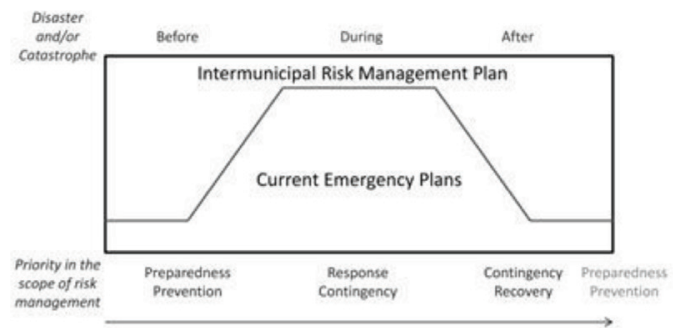

Figure 1. Articulation principles between the IRMP and the existing emergency plans.

\section{STUDY AREA}

The Intermunicipal Community of the Region of Coimbra is an integral part of the NUT II Central Region, comprising coastal and inland municipalities (Figure 2) corresponding to a resident population of approximately 460000 inhabitants.

This region, which extends from the Atlantic Ocean coast to the reliefs of the Central Massif, formed by the Estrela, Açor and Lousã mountains, is therefore characterized by morphological, geological and climatological heterogeneity. Agricultural areas dominate the western, lowland, sector of the region, while natural and semi-natural areas prevail on the higher elevations of the eastern sector (Figure 2).

Main cities - Figueira da Foz and Coimbrahave in common the relation with the main river, the Mondego, which connect them along a vast and economically relevant floodplain.

A wide range of natural processes affecting the CIM have been identified within the framework of the PROT-Center, the regional spatial planning instrument (CCDRC, 2008). From those processes - which susceptibility cartography is presented in Figure 3-some should be highlighted: seismicity, natural radioactivity, landslides, coastal erosion, flooding (whether urban, fluvial or coastal), forest fires, heat and cold waves, as well as the technological hazards associated with the transport, storage and processing of dangerous substances by road, rail and sea.

The urban context of the CIM of Coimbra region also emphasizes the importance of other processes and associated impacts, such as those related to storms and strong winds, urban fires, the structural vulnerability conditions of buildings and

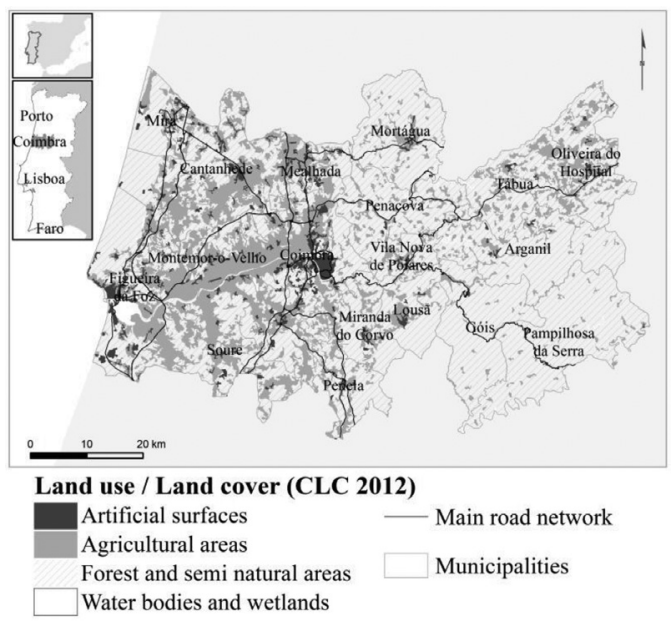

Figure 2. Geographical context of the region of Coimbra. 


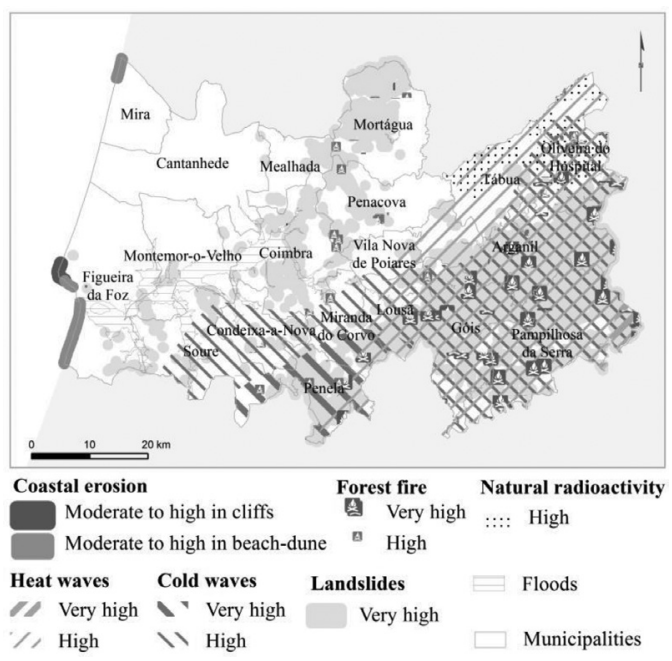

Figure 3. Mapping of the susceptibility to the main natural hazards in the region of Coimbra.

infrastructure and equipment. Built heritage and factors related to people and material mobility are also identified as relevant risk components to be considered in planning instruments.

\section{EMERGENCY PLANNING BACKGROUND}

The first analysis began with the diagnosis of the 19 emergency plans of the municipalities that compose the CIM of Coimbra region, in order to assess their contents and the way in which the different territories are articulated with the different actors in the response to a major accident or catastrophe.

The second analysis dealt with a database of 80000 big and small disaster events, between 2007 and 2015, which enabled the characterization of the typology of occurrences that more frequently affect the territory, as well as the associated consequences.

Table 1 shows the type of parameters that were evaluated in each of the afore-mentioned instruments, as well as the respective data source.

From the analysis carried out on the different instruments, it was possible to verify the existence of relevant differences in the way the parameters are addresses by the distinct plans, even in neighboring municipalities, which presented as gaps and discrepancies in risk planning, taking into account that at intermunicipal level the procedures and the entities involved in are not always the same, or follow distinct procedures. This reduces the consistency needed for an intermunicipal management approach.

When referring to the intervenient actors in the plan, civil protection agents (security and rescue forces) as well as all entities that represent sectors
Table 1. Parameters and sources of the emergency planning instruments and disaster database.

\begin{tabular}{|c|c|c|}
\hline Instrument & Parameter & Source \\
\hline $\begin{array}{l}\text { Emergency } \\
\text { plans }\end{array}$ & $\begin{array}{l}\text { Criteria for plan } \\
\text { activation } \\
\text { Plan intervenients } \\
\text { Early warning and } \\
\text { communication } \\
\text { tools } \\
\text { Private sector } \\
\text { participation }\end{array}$ & Municipalities \\
\hline $\begin{array}{l}\text { Database of } \\
\text { emergency } \\
\text { rescue } \\
\text { database }\end{array}$ & $\begin{array}{c}\text { Type and number } \\
\text { of occurrences }\end{array}$ & $\begin{array}{r}\text { District civil } \\
\text { protection } \\
\text { command }\end{array}$ \\
\hline
\end{tabular}

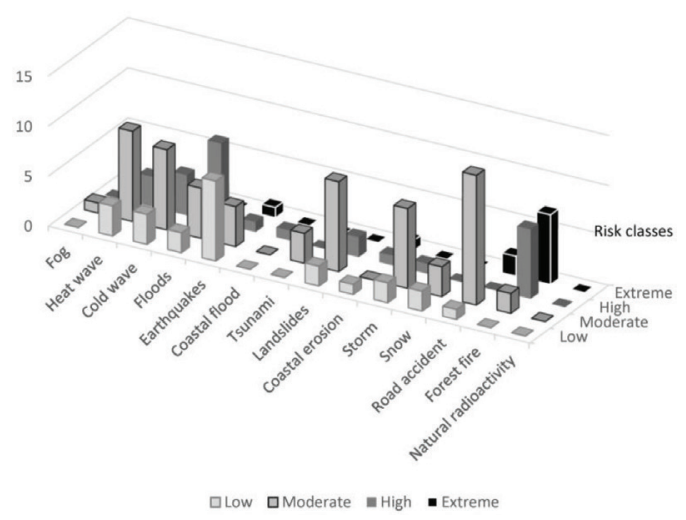

Figure 4. Mains types of risk in the Coimbra region as classified in the risk matrices of the municipal emergency plans.

that contribute to civil protection actions (associations, institutes, universities) are being considered.

Another of the parameters studied was the representativeness of the risks in municipal emergency plans and how they are concordant with the list of risks addressed by the IRMP.

Thus, Figure 4 represents the number of municipalities that attributed a given risk class (y-axis) following a risk matrix that crosses probability and severity - to each type of risk to be considered in the IRMP (x-axis).

The analysis of the graph allows to conclude that there are some type of risks that affect only part of the territory (cf. Figure 3), for example, natural radioactivity and risks related to coastal areas (inundation, erosion and tsunami). These risks are represented in the risk matrices of the municipal emergency plans with low or moderate risk.

On the other side, Figure 3 shoes that are some processes with much higher ubiquity in the region, such as road accidents, forest fires, floods, landslides, earthquakes, cold waves and heat waves. 
Number of occurrences

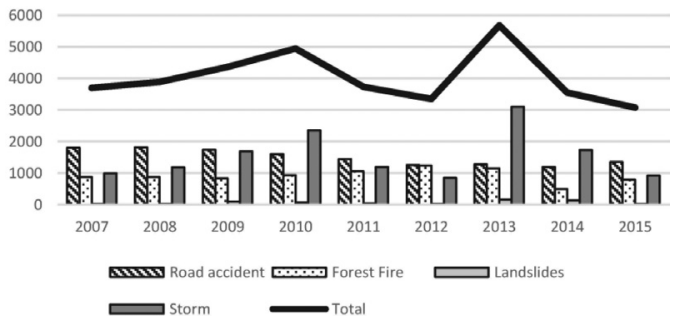

Figure 5. Annual distribution of disaster occurrences in which civil protection agents intervened in rescue operations.

Apart from representativeness, higher risk classes (extreme and high) are given to the risk of forest fire, flood and fog. The moderate risk class is more often associated with road accidents, landslides and adverse weather conditions - cold and heat waves, fog again and storms. Earthquakes are the only risk that most often appears associated with a low risk class.

The analysis carried out is merely representative of the contents of the municipal emergency plans, allowing having a general view on the impact of the management options to include in the IRMP in the context of Coimbra region's municipalities.

Regarding the database of emergency rescue operations, the events that occur most frequently are storms, followed by road accidents, forest fires and finally landslides.

Figure 5 represents the annual distribution of the disaster occurrences that appear in the emergency rescue database. It is possible to verify that the risks with the greatest number of events are road accidents, with only two years (2010 and 2013), where the storms totalized a larger number of occurrences. Of the remaining values, forest fires appear in third place, taking into account the seasonality with which they occur (mostly between May and September), and finally the landslides that present a larger number in the years of 2013 and 2014.

\section{TERRITORIAL VULNERABILITY}

A territory's vulnerability to natural and technological hazards can be represented in a wide range of dimensions. In this assessment, the most relevant dimension considered was that related directly to the population's safety and resilience, usually connected with the concept of social vulnerability. In such concept the collected variables attempt to represent population's socioeconomic status, gender, race and ethnicity, age, employment, family structure, education, housing conditions, medical services, social dependency and special needs (cf. Chen et al., 2013). Additionally, the conducted assessment included other dimensions, such as the coverage by social equipment (health and education), commercial stores providing basic needs, ATM's, civil protection assets and road network. These dimensions try to address an understanding of the existing support capacity that help attenuate impacts and facilitate recovery.

The methodological approach follows the statistical procedures defined in regard to the calculation of the Social Vulnerability Index (Cutter et al., 2003), although trying to incorporate the abovementioned additional dimensions.

An initial set of 36 variables was defined and their data collected and integrated at the statistical block level - this level of disaggregation represents a total of 826 units of analysis. After a process of multicolinearity elimination, a final set of data from 33 variables was used to perform Principal Component Analysis (PCA). The scores of the resulting principal components are summed without weighing and classified according to the Standard Deviation (SD) as follows: Very Low (VL) to values lower than -1.5 $\mathrm{SD}$; Low (L) to values between $-1.5 \mathrm{SD}$ and $-0.5 \mathrm{SD}$; moderate $(\mathrm{M})$ to values between $-0.5 \mathrm{SD}$ and $0.5 \mathrm{SD}$, High $(\mathrm{H})$ to values between $0.5 \mathrm{SD}$ and $1.5 \mathrm{SD}$ and Very High $(\mathrm{VH})$ to values higher than 1.5 SD.

Mapping of territorial vulnerability for the Coimbra region, at this level of detail, presents a complex and heterogeneous geographical configuration (Figure 6). Nevertheless, it is observable that the municipality of Coimbra presents in general low and very low territorial vulnerability, while the eastern, mountainous sector of the region displays the higher scores.

Cutting the explicative components at an Eigenvalue of 1 , a total of seven principal components (FAC's) is obtained that explains $72.7 \%$ of the total variance. The seven FAC's are describing specific forcers of vulnerability: FAC1 - Coverage by social equipment and services; FAC2 - Residential and familiar context; FAC3 - Employment and housing conditions; FAC4 - Age structure; FAC5 - Gender; FAC6 - Mobility; FAC7 - Housing occupancy. Mapping and understanding each FAC is an essential output for the definition and specific and adapted policies and measures with reflect on vulnerability and resilience, quite beyond the specific field of intervention of emergency planning.

\section{EXPECTATIONS FOR INTERMUNICIPAL RISK MANAGEMENT}

An intermunicipal approach to risk management requires an interaction between the different actors of the prevention, emergency and rehabilitation phases of the disaster cycle. Perceiving 


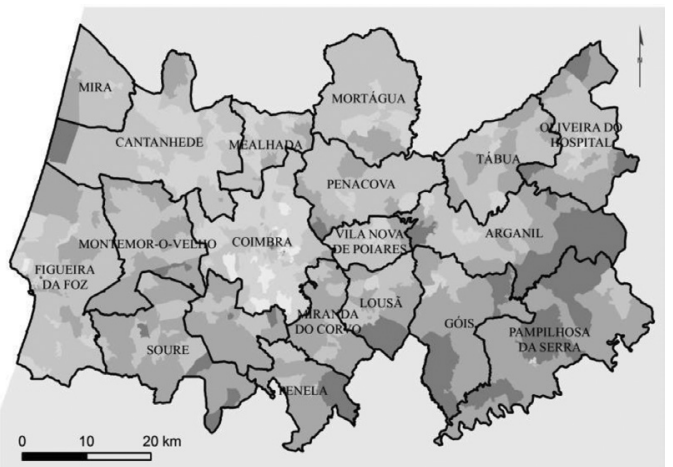

Territorial vulnerability

Very high $\square$ High $\square$ Moderate Low $\square$ Very low

Figure 6. Preliminary results of the territorial vulnerability assessment.

and incorporating their know-how, main needs and expectations is key in allowing a more efficient and recognized definition of procedures and options in the IRMP of the Coimbra region. Only a joint and articulated planning and operation of the municipalities, along with the pivotal role of the CIM, and the other civil protection agents and stakeholders can contribute to the major goal of reducing the risk of disasters and impacts, when they are inevitable.

In this context, the different municipal representatives and practitioners of civil protection policies of the municipalities that compose the CIM of Coimbra were assembled and participated in a workshop to share their current situation in emergency planning and future expectations about the ongoing process of elaboration of the IRMP.

The participatory methodology designated as Q-methodology was adopted, a method used to evaluate the way people think or feel about a given topic (e.g. Steelman \& Maguire, 1999; Robbins \& Krueger, 2000).

Around 40 participants were asked to position themselves in terms of level of agreement in regard to a set of 25 statements (Figure 7). The statements addressed topics related to current and future emergency planning and, more broadly, risk planning. Specific issues such as inter-entity articulation, intermunicipal response, communications systems, warning and alert, relevance of multisectorial approach, were also contemplated.

From the resulting positioning, it was possible to conclude that there is little agreement on the existing emergency planning instruments (Figure 8). Regarding the objectives of intermunicipal risk management, there is some agreement among the respondents about the need to improve the articulation between public and private entities, as well as the mechanisms to be adopted in the prevention, contingency and rehabilitation phases.

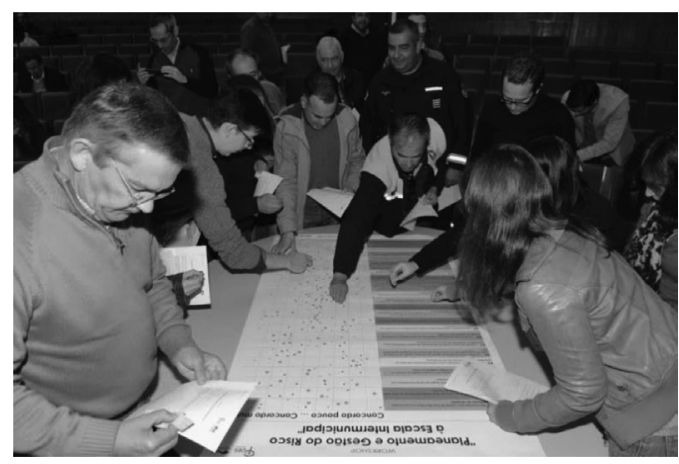

Figure 7. Participatory dynamic according to the technic of Q-methodology, with the participation of the local civil protection managers and practitioners.

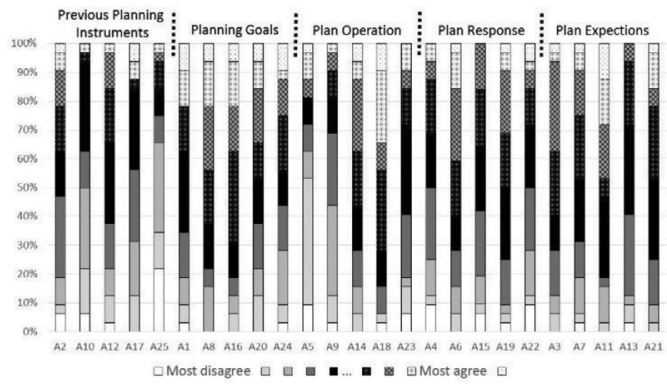

Figure 8. Levels of agreement in face of the type of statement addressed in the Q-methodology workshop.

At the level of operations, there is an expectations to improve communications systems and the involvement of more entities. In the participants' opinion, at the response level the IRMP should improve operational response, warning and alert systems and political articulation. Finally, there is an expectation that an articulated inter-municipal management of risks may improve planning tools, and bring the ability to mobilize financial resources, as well as to harmonize risk mapping, conciliating risk assessment between municipalities.

\section{CONSTRUCTING THE INTERMUNICIPAL RISK MANAGEMENT PLAN}

The construction of the IRMP is being planned based on the assessment knowledge produced and briefly described.

A relevant aspect to consider in this phase is the diagnosis of existing monitoring systems, as the CIM is involved in complementary projects that aim at improving the early warning and communications capacity at the regional and local level. 
Such IT systems will be considered in the plan. For each risk, a matrix was elaborated which describes the current scale at which monitoring is performed and (second column) synergies of multi-risk potential are explored, as the same monitoring equipment might contribute to inform about diverse types of hazard processes (Table 2).

The current scale at which, considering a normal scenario, emergency response is conducted was defined, in order to predict the level of involvement needed to address the quotidian disaster occurrences and to prepare the contingency of activities and functions (Table 3 ).

The nature and characteristics of some types of risks require a stronger level or recognition between stakeholders and articulations between institutions. This assessment was also performed, highlighting the risks of heat and cold waves, floods, coastal erosion, earthquakes, tsunamis, natural radioactivity and forest fires.

The structure of the IRMP under elaboration attempts to consider thus all this dimensions of intervention, from the prevention, emergency, contingency and recovery phases of the disaster.

The structure of the IRMP has a strong link between the level of action foreseen in the emergency plans for civil protection and the level of exante and post-disaster action, that is, a level that favors adaptation, prevention and contingency to

Table 2. Existing scale of monitoring systems and potential for local improvement of multi-risk monitoring of the main risks of the region of Coimbra.

\begin{tabular}{llll}
\hline & $\begin{array}{l}\text { Hazard } \\
\text { monitoring and } \\
\text { early warning }\end{array}$ & $\begin{array}{l}\text { Potential } \\
\text { for multi-risk } \\
\text { monitoring }\end{array}$ \\
\cline { 2 - 5 } & & &
\end{tabular}

Table 3. Normal scale of emergency response and need for multilevel articulation of the main risks in the CIM of the region of Coimbra.

\begin{tabular}{|c|c|c|c|c|c|}
\hline \multirow[b]{2}{*}{ Risks } & \multicolumn{4}{|c|}{$\begin{array}{l}\text { Normal scale of } \\
\text { emergency response }\end{array}$} & \multirow{2}{*}{ 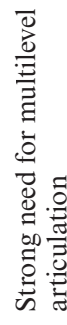 } \\
\hline & 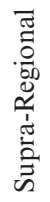 & 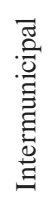 & 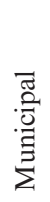 & శ్ర్ల & \\
\hline Snow, ice and fog & & & $\mathrm{x}$ & $\mathrm{x}$ & \\
\hline Heat and cold waves & & & $\mathrm{x}$ & $\mathrm{x}$ & $\mathrm{x}$ \\
\hline Storms & & & $\mathrm{x}$ & & \\
\hline Floods & & $\mathrm{x}$ & $\mathrm{x}$ & $\mathrm{x}$ & $\mathrm{x}$ \\
\hline Flash floods & & & $\mathrm{x}$ & $\mathrm{x}$ & \\
\hline Coastal floods & & & $\mathrm{x}$ & $\mathrm{x}$ & \\
\hline Coastal erosion & $\mathrm{x}$ & & & $\mathrm{x}$ & $\mathrm{x}$ \\
\hline Earthquakes & $\mathrm{x}$ & & $\mathrm{x}$ & & $\mathrm{x}$ \\
\hline Tsunamis & $\mathrm{x}$ & & & $\mathrm{x}$ & $\mathrm{x}$ \\
\hline Landslides & & & & $\mathrm{x}$ & \\
\hline Natural radioactivity & & & & $\mathrm{x}$ & $\mathrm{x}$ \\
\hline Road accident & & $\mathrm{x}$ & $\mathrm{x}$ & $\mathrm{x}$ & \\
\hline Forest fires & $\mathrm{x}$ & $\mathrm{x}$ & $\mathrm{x}$ & $\mathrm{x}$ & $\mathrm{x}$ \\
\hline
\end{tabular}

disasters. In effect, municipal decision-makers in the area of Civil Protection need - in addition to trained procedures to help and combat danger processes - structures, procedures, instructions for coordination and identification of responsibilities that act in parallel and in interaction with the emergency intervenient, guaranteeing the contingency and the restoration of the day-to-day and vital functions.

The IRMP is being defined upon three main parts: framing, execution and implementation actions.

First part includes the definition of the scope of the plan, the identification of planning instruments with which it will be articulated, the definition and characterization of the intervention geographical area (which includes hazard, vulnerability, exposure and risk analysis).

The second part, execution, is the most comprehensive and relevant as all the procedures and responsibilities are here defined, considering 3 moments: pre-emergency, emergency and postemergency. The procedures and responsibilities are structures in intervention areas that include financial and administrative management, monitoring, logistics, communications, public information, evacuation and rehousing, public order maintenance, social and medical services, vital functions maintenance and mobility maintenance.

The last part details general and specific implementation actions, defining the CIM structure responsible for the Plan implementation, its 
chronograms and action files. Complementary material will be prepared, in the form of fact sheets, detailing the actions, the required human and material resources, the demanded level of institutional involvement, the lead time and the financial costs potentially necessary.

\section{CONCLUSIONS}

The elaboration of an intermunicipal plan for the management of multi-risks is a challenge, considering the diversity of goals that are expected to be achieved and the multitude of intervenient with implications on the efficient prosecution of such goals. Nevertheless, there is in fact a gap in this area in the current institutional and instrumental building related to a broader perspective of risk governance.

The analysis and diagnoses conducted so far stress the need to improve prevention and contingency, before and during emergencies. This includes a strong political commitment with improving monitoring systems.

The expectations in regard to the IRMP highlight the need to go beyond the emergency planning paradigm. This is to say, to include more thoroughly the planning of ex-ante and post-disaster actions. In this new paradigm, preparedness and prevention, along with contingency and recovery, must also be subject to detailed and articulated planning procedures.

Using a risk-based approach, the Intermunicipal Community of the Coimbra Region recognizes that long-term benefits in disaster risk reduction are only obtained through integrative and holistic planning, where resources' and information sharing are key factors.

The IRMP allows political and technical managers to choose among competing priorities and selectively allocate resources in a competitive way with other regions. It also allows entities and stakeholders to be responsible for justifying management options, promoting an equitable distribution of resources and using innovative and technologically advanced tools.

The intermunicipal planning framework is expected to increase the resilience of a complex territory, focusing on the maintenance of multifunctionality, on preparedness and prevention, and on contingency and recovery, centered on communities and local institutions. The current achievements on the definition of a strategy for the intermunicipal management of risks, reflected in the IRMP, revealed themselves as a new and fruitful challenge that reflects a broader perspective in risk governance for the region.

\section{ACKNOWLEDGMENTS}

This work is funded by Portuguese funds through FCT-Foundation for Science and Technology, I.P., in the scope of project "FORLAND-Hydrogeomorphologic risk in Portugal: driving forces and applications for land use planning (PTDC/ ATPGEO/1660/2014)".

\section{REFERENCES}

Alexander, D. 2005. Towards the development of a standard in emergency planning. Disaster Prevention and Management: An International Journal 14(2): 158-175.

CCDR-C, 2008. Spatial Planning Regional Plan of the Coimbra Region. Coordination Commission for the Regional Development of the Coimbra Region.

Chen W., Cutter, S.L., Emrich, C.T. \& Shi, P. 2013. Measuring social vulnerability to natural hazards in the Yangtze River Delta region, China. International Journal of Disaster Risk Science 4(4): 169-81.

Cutter S.L., Boruff, B.J. \& Shirley, W.L. 2003. Social vulnerability to environmental hazards. Social Science Quarterly 84(2): 242-61.

Flage, R. \& Amundrud, O. 2015. Overall regional risk analysis of four Norwegian municipalities. In Safety and Reliability: Methodology and Applications-Nowakowski et al. (eds.) Taylor \& Francis Group, London, pp. 361-369.

Hassel, H. 2012. Risk and vulnerability analysis in practice: evaluation of analyses conducted in Swedish municipalities. Natural Hazards 63(2): 605-628.

Henstra, D. 2010. Explaining local policy choices: a multiple streams analysis of municipal emergency management. Canadian Public Administration 53(2): 241-258.

Murphy, B.L. 2007. Locating social capital in resilient community-level emergency management. Natural Hazards 41(2): 297-315.

Pech, P., Duplan, C., Robin-Chevallier, L. \& Fevrier, R. 2016. How to achieve local resilience to flood risks by increasing solidarity: The example of the "Syndicat Mixte" (Inter-Municipal Cooperation Structure) of the French Territory of Belfort-Montbéliard. Journal of Water Resource and Protection 8(4): 493-504.

Robbins, P. \& Krueger, R. 2000. Beyond bias? The promises and limits of Q Method in Human Geography. Professional Geographer 52(4): 636-648.

Steelman, T.A. \& Maguire, L.A. 1999. Understanding participant perspective: Q-Methodology in national forest management. Journal of Policy Analysis and Management 18(3): 361-388.

UNISDR 2015. Sendai Framework for Action 20152030. United Nations Office for Disaster Risk Reduction. 